\title{
Free radicals produced by the oxidation of gallic acid and catechin derivatives
}

\begin{abstract}
Gallic acid and catechin derivatives were oxidized in alkaline solution $(\mathrm{pH} 10.0-13.0)$ with $\mathrm{K}_{3}\left[\mathrm{Fe}(\mathrm{CN})_{6}\right]$ under anaerobic conditions, and electron spin resonance (ESR) spectra of the radicals produced were measured. Gallic acid, epicatechin gallate, gallocatechin gallate, epigallocatechin, and epigallocatechin gallate showed hyperfine structures. Gallic acid was found to be oxidatively $\mathrm{C}-\mathrm{O}$ coupled in alkaline solution ( $\mathrm{pH} 10.5-12.0)$. It was found that an unpaired electron delocalized over gallocatechin gallate and epigallocatechin molecules, but was localized on the galloyl group and the A-ring of epicatechin gallate and epigallocatechin gallate. The galloyl group of gallo-catechin gallate was readily alkalihydrolyzed but those of epicatechin gallate and epigallocatechin gallate were resistant to alkaline hydrolysis.
\end{abstract}

Key words ESR · Free radical · Gallic acid · Catechin derivatives

\section{Introduction}

The antioxidative activities of tannins have been evaluated on their scavenging effects against 1,1-diphenyl-2-picrylhydrazyl radical, superoxide anion, singlet oxygen, and hydroxyl radical. ${ }^{1-5}$ There is evidence that tannin radicals were produced in the scavenging processes ${ }^{4,6}$ However, there have been few reports on electron spin resonance (ESR) spectra of tannin radicals, ${ }^{3,7,8}$ all of which concerned the production of tannin radicals by autoxidation in alkaline solutions. In the case of autoxidation, because dissolved oxygen in alkaline solution oxidizes tannins, it is difficult to quantitatively oxidize tannins, and a large linewidth is obtained because of the paramagnetism of the dissolved oxygen molecule.

In this study, gallic acid and catechin derivatives were oxidized with $\mathrm{K}_{3}\left[\mathrm{Fe}(\mathrm{CN})_{6}\right]$ in buffer solutions ( $\mathrm{pH} 10.0$ 13.0) under anaerobic conditions and ESR spectra of radicals produced were measured.

T. Oniki $(\bowtie) \cdot$ U. Takahama

Kyushu Dental College, Kitakyushu 803-8580, Japan

Tel. +81-93-582-1131; Fax +81-93-581-3202

\section{Experimental}

Materials

Gallic acid, (-)-epicatechin (EC), (-)-epicatechin gallate (ECG), (-)-gallocatechin (GC), (-)-gallocatechin gallate (GCG), (-)-epigallocatechin (EGC), and (-)epigallocatechin gallate (EGCG) were obtained from Wako. Gallic acid was recrystallized twice from water.

\section{ESR measurement}

ESR spectra were measured using a Jeol JES-FE1XG spectrometer operating at $9.5 \mathrm{GHz}$ with $100-\mathrm{kHz}$ field modulation. Spectra were obtained with a microwave power of $1 \mathrm{~mW}$ and with a modulation amplitude of $0.002 \mathrm{mT}$.

Buffer solutions used were $\mathrm{NaHCO}_{3}-\mathrm{NaOH}(\mathrm{pH} 10.0$ 11.0), $\mathrm{Na}_{2} \mathrm{HPO}_{4}-\mathrm{NaOH}(\mathrm{pH} 11.0-12.0)$, and $\mathrm{NaOH}-\mathrm{KCl}$ ( $\mathrm{pH}$ 12.0-13.0). Gallic acid or catechin derivatives and $\mathrm{K}_{3}\left[\mathrm{Fe}(\mathrm{CN})_{6}\right]$ were dissolved at the same time in a buffer solution under argon, and then introduced into a quartz flat cell to measure the ESR spectra. The concentration of $\mathrm{K}_{3}\left[\mathrm{Fe}(\mathrm{CN})_{6}\right]$ was $1 \mathrm{mmol} \mathrm{dm}^{-3}$ and the concentration of gallic acid or catechin derivatives was twice that of $\mathrm{K}_{3}\left[\mathrm{Fe}(\mathrm{CN})_{6}\right]$ unless otherwise noted.

\section{Results and discussion}

When gallic acid was oxidized at $\mathrm{pH}$ 13.0, a simple ESR signal was observed (Fig. 1). The signal showed a hyperfine structure due to two equivalent protons in the gallate radical. The hyperfine splitting constant $\left(a_{\mathrm{H}}\right)$ was $0.11 \mathrm{mT}$.

The signal intensities of phenoxyl radicals generally decreases with decreasing $\mathrm{pH}$ in buffer solutions. When gallic acid was oxidized at low $\mathrm{pH}$, another signal was observed (Fig. 1). The new signal showed a hyperfine structure due to three nonequivalent protons $\left(a_{\mathrm{H}}=0.077 \mathrm{mT}, 0.047 \mathrm{mT}\right.$, and $0.014 \mathrm{mT}$ ), and did not show the presence of the two equivalent protons of the gallyl group. The ratio of the two signal 

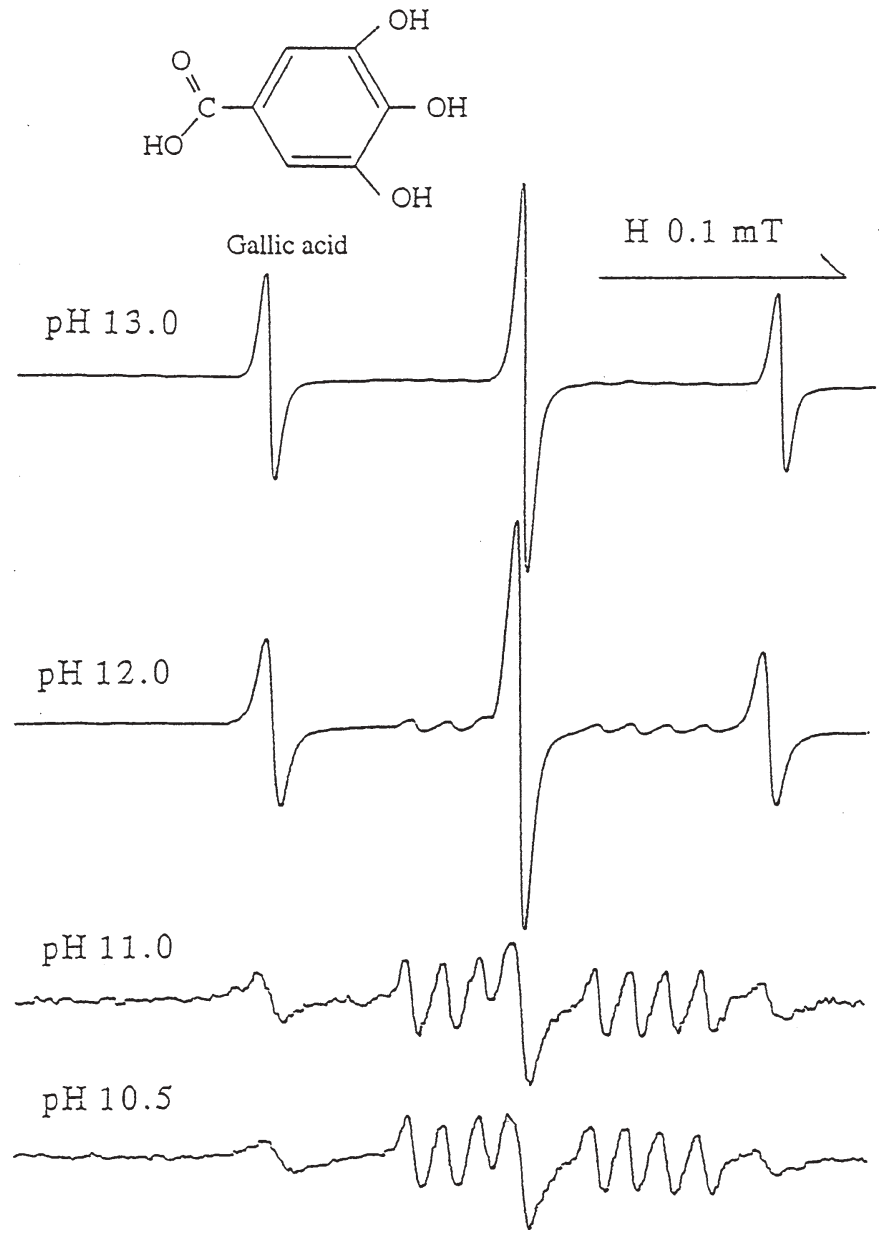

Fig. 1. Electron spin resonance (ESR) spectra obtained by the oxidation of gallic acid in different buffer solutions

intensities (new signal/gallate signal) increased with decreasing $\mathrm{pH}$. The ratio did not depend directly on the concentration of gallic acid, whereas the ratio increased when the concentration was increased together with the concentration of $\mathrm{K}_{3}\left[\mathrm{Fe}(\mathrm{CN})_{6}\right]$ (Fig. 2). It was found from high performance liquid chromatography (HPLC) that oxidation products at $\mathrm{pH} 13.0$ and 10.5 were different from each other. The data suggest that the new signal was due to a dimer radical in which two gallic acid units oxidatively coupled between the ortho-carbon and the meta-hydroxyl oxygen (dehydrodigallic acid) (Fig. 2). Other possible dimer structures could not explain the presence of three magnetically nonequivalent protons.

Li et al. ${ }^{8}$ obtained the ESR signal of an EC radical obtained by autoxidation in $1 \mathrm{~mol} \mathrm{dm}^{-3} \mathrm{NaOH}$ solution. However, we could not detect the signal of the EC radical because of the very short life-time of the radical. ECG showed a very simple ESR signal, with hyperfine splitting constants of $0.11 \mathrm{mT}$, due to two equivalent galloyl protons, and $0.015 \mathrm{mT}$, due to another proton (Fig. 3). It was uncertain which proton contributed to the $a_{\mathrm{H}}$ value of $0.015 \mathrm{mT}$. When ECG was oxidized after dissolution in a buffer solution ( $\mathrm{pH} 13.0)$ and standing for $1 \mathrm{~h}$, the ESR signal due to the gallate radical (Fig. 1) was only slight (Fig. 3). This suggests that the galloyl group in ECG was not appreciably alkali-hydrolyzed at $\mathrm{pH}$ 13.0.

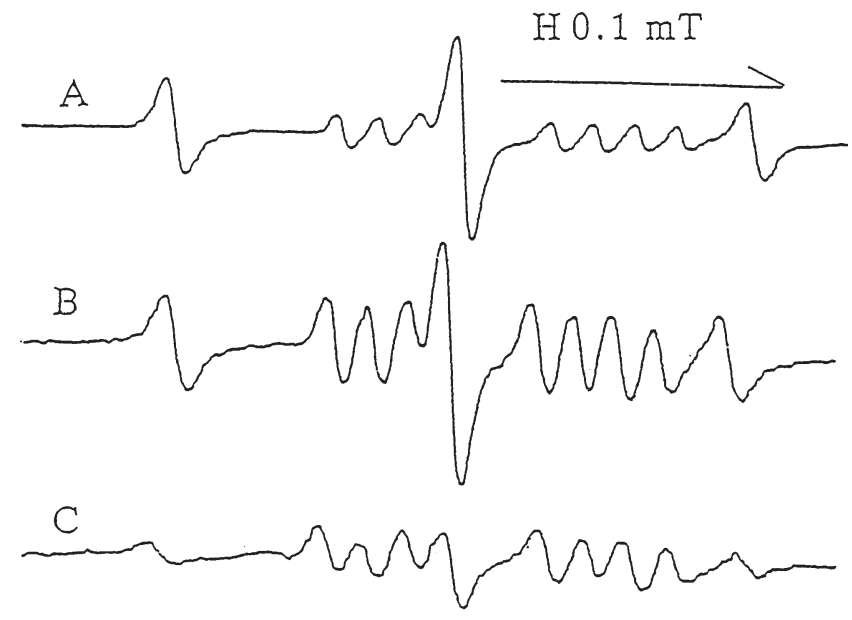<smiles>O=C(O)c1ccc(O)c(Oc2c(O)ccc(O)c2O)c1O</smiles>

Fig. 2. Changes in ESR signals of gallic acid oxidized at $\mathrm{pH} 11.5$ due to the concentration of $\mathrm{K}_{3}\left[\mathrm{Fe}(\mathrm{CN})_{6}\right] . A, \mathrm{~K}_{3}\left[\mathrm{Fe}(\mathrm{CN})_{6}\right] 1 \mathrm{mmol} \mathrm{dm}^{-3} ; B$, $\mathrm{K}_{3}\left[\mathrm{Fe}(\mathrm{CN})_{6}\right] 2 \mathrm{mmol} \mathrm{dm}^{-3} ; C, \mathrm{~K}_{3}\left[\mathrm{Fe}(\mathrm{CN})_{6}\right] 3 \mathrm{mmol} \mathrm{dm}^{-3}$. Concentration of gallic acid was twice that of $\mathrm{K}_{3}\left[\mathrm{Fe}(\mathrm{CN})_{6}\right]$

When GC was oxidized at pH 13.0, a broad ESR signal was observed, perhaps due the short relaxation time of the radical (Fig. 4).

When GCG was oxidized at pH 13.0, ESR signals due to three kinds of radicals were observed (Fig. 4). Two of the signals were attributable to the gallate radical (Fig. 1) and the ECG radical (Fig. 3). GCG radical showed hyperfine structure due to two equivalent galloyl protons $\left(a_{\mathrm{H}}=\right.$ $0.10 \mathrm{mT})$, two equivalent gallyl protons $\left(a_{\mathrm{H}}=0.43 \mathrm{mT}\right)$, and another proton $\left(a_{\mathrm{H}}=0.25 \mathrm{mT}\right)$. It was found that an unpaired electron was delocalized over the GCG molecule. When GCG was oxidized after dissolution in a buffer solution ( $\mathrm{pH} 13.0)$ and standing for $1 \mathrm{~h}$, the ESR signal observed was due almost exclusively to the gallate radical (Fig. 4). This suggests that the galloyl group in GCG was completely alkali-hydrolyzed during incubation for $1 \mathrm{~h}$.

EGC showed an ESR signal containing a hyperfine structure due to two equivalent gallyl protons $\left(a_{\mathrm{H}}=0.086 \mathrm{mT}\right)$ and three nonequivalent protons $\left(a_{\mathrm{H}}=0.47,0.028\right.$, and $0.015 \mathrm{mT}$ ) (Fig. 5). The data also suggest that an unpaired electron is delocalized over the EGC molecule. EGCG showed a hyperfine structure due to two equivalent galloyl protons $\left(a_{\mathrm{H}}=0.092 \mathrm{mT}\right)$, and two nonequivalent protons $\left(a_{\mathrm{H}}=0.36\right.$ and $0.032 \mathrm{mT}$ ) (Fig. 5). Hyperfine structure due to the two equivalent gallyl protons was not observed. It was found that no unpaired electron delocalization occurred on the gallyl group. This tendency was also observed for ECG (Fig. 3). EGCG contained a slight amount of GCG (Fig. 4) and gallic acid (Fig. 1). The galloyl group in EGCG was not appreciably hydrolyzed after $1 \mathrm{~h}$ at $\mathrm{pH} 13.0$ (Fig. 5). 


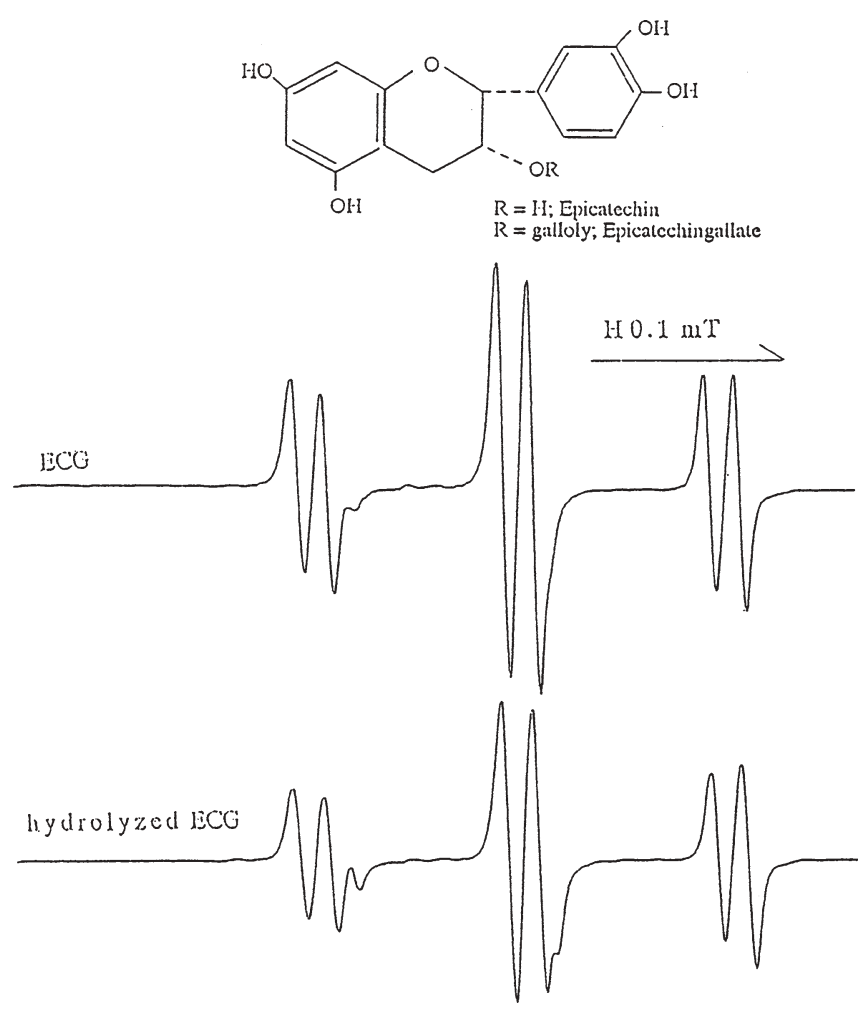

Fig. 3. ESR spectra obtained by the oxidation of epicatechin gallate $(E C G)$ and alkali-hydrolyzed ECG at pH 13.0

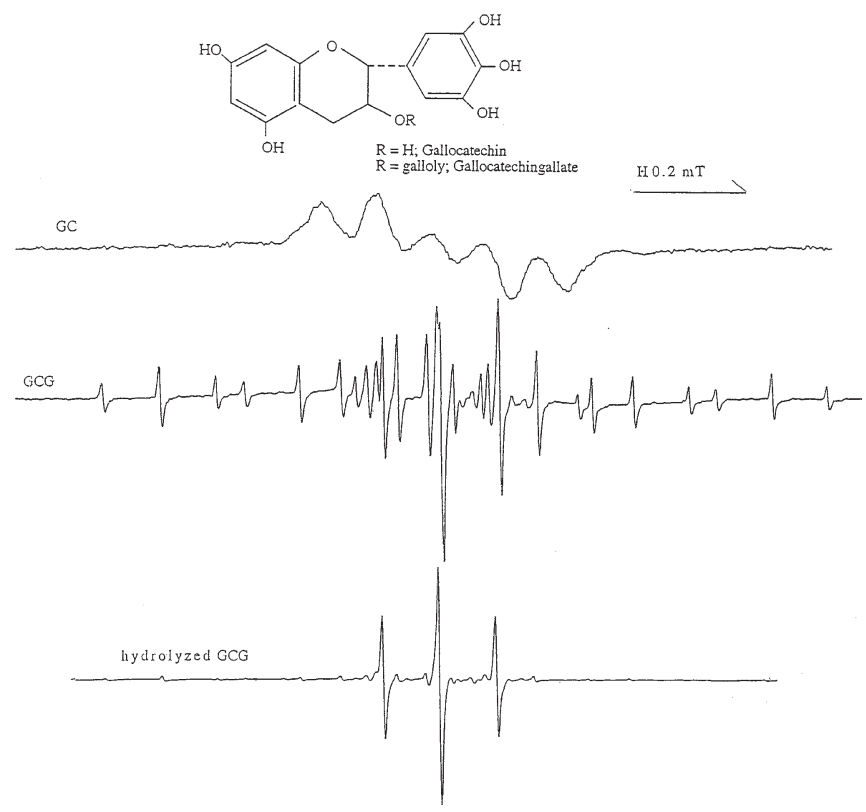

Fig. 4. ESR spectra obtained by the oxidation of gallocatechin $(G C)$, gallocatechin gallate $(G C G)$, and alkali-hydrolyzed GCG at $\mathrm{pH} 13.0$

Galloyl and hexahydroxydiphenoyl moieties are present in hydrolyzable tannins. ${ }^{9}$ ESR signals are expected to be observed when hydrolyzable tannins are oxidized using this method.

\section{Conclusions}

When gallic acid was oxidized in alkaline solutions $(\mathrm{pH}$ 10.5-12.0), a dimer was produced through carbon-oxygen

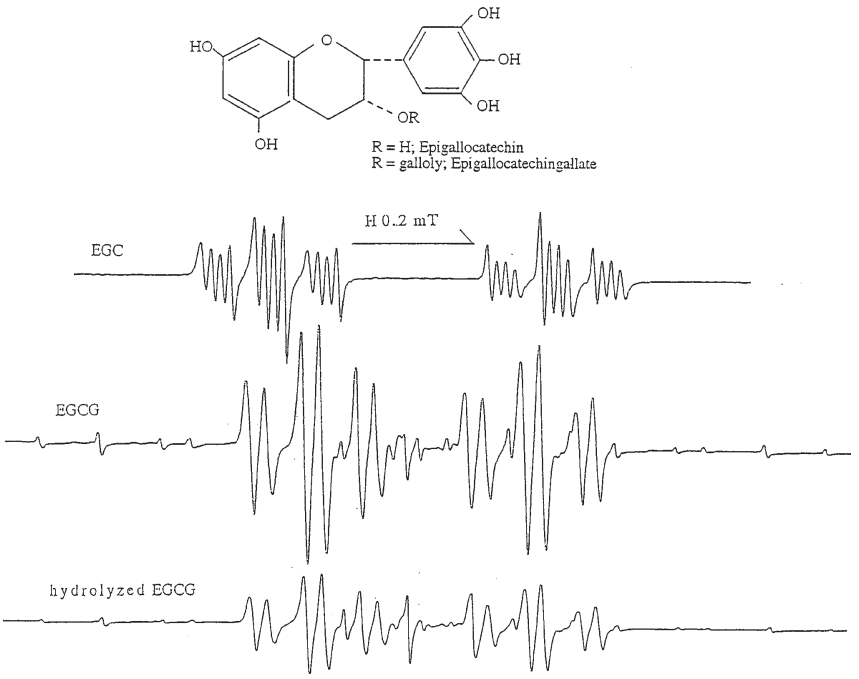

Fig. 5. ESR spectra obtained by the oxidation of epigallocatechin $(E G C)$, epigallocatechin gallate $(E G C G)$, and alkali-hydrolyzed EGCG at $\mathrm{pH} 13.0$

coupling and an ESR signal of the dimer radical was observed. The spin densities in catechin derivatives and the rates of alkali-hydrolysis of galloyl groups in catechin derivatives were found to be very sensitive to their steric structures.

\section{References}

1. Uchida S, Edamatsu R, Mori A, Nonaka G, Nisioka I, Niwa M, Ozaki M (1987) Condensed tannins scavenge active oxygen free radicals. Med Sci Res 15:831-832

2. Uchida S, Edamatsu R, Hiramatsu M, Mori A, Nonaka G, Nishioka I, Niwa M, Ozaki M (1988) Radical scavenging action of condensed tannins. Neurosciences 14:243-244

3. Yoshida T, Mori A, Hatano T, Okumura T, Uehara I, Komagoe K, Fujita Y, Okuda T (1989) Studies on inhibition mechanism of autoxidation by tannins and flavonoids. V. Radical scavenging effects of tannins and related polyphenols on 1,1-diphenyl-2-picrylhydrazyl radical. Chem Pharm Bull 37:1919-1921

4. Hatano T, Edamatsu R, Hiramatsu M, Mori A, Fujita Y, Yasuhara T, Yoshida T, Okuda T (1989) Effects of the interaction of tannins with co-existing substances. VI. Effects of tannins and related polyphenols on superoxide anion radical, and on 1,1-diphenyl-2picrylhydrazyl radical. Chem Pharm Bull 37:2016-2021

5. Jovanovic S, Hara Y, Steenken S, Simic MG (1995) Antioxidant potential of gallocatechins. A pulse radiolysis and laser photolysis study. J Am Chem Soc 117:9881-9888

6. Masaki H, Atsumi T, Sakurai H (1995) Peroxyl radical scavenging activities of hamamelitannin in chemical and biological systems. Free Rad Res 22:419-430

7. Sakagami H, Jiang Y, Kusama K, Atsumi T, Ueha T, Toguchi M, Iwakura I, Satoh K, Ito H, Hatano T, Yoshida T (2000) Cytotoxic activity of hydrolyzable tannins against human oral tumor cell lines - a possible mechanism. Phytomedicine 7:39-47

8. Li W, Guo Q, Zhao B, Shen S, Hou J, Xin W (1998) ESR spectroscopy structural analysis of the semiquinone free radicals of green tea polyphenols and their components. Chinese J Mag Resonance 15:507-513

9. Haddock EA, Gupta RK, Al-Shafi SMK, Haslam E (1982) The metabolism of gallic acid and hexahydroxydiphenic acid in plants. Part 1. Introduction, naturally occurring galloyl esters. J Chem Soc Perkin Trans I 1982:2515-2524 